\title{
Thermal stability and Anti-Corrosion analysis of alloy coatings on Overhead Ground Wires
}

\author{
Kai Guo ${ }^{1, a}$, Yishu Du ${ }^{2, b}$, Shuang Liü ${ }^{1, c}$, Xingeng $\mathrm{Li}^{1, \mathrm{~d}}$, Zengwu Yue ${ }^{1,}$, Min $\mathrm{Fu}^{1,}$, \\ Xuegang Wang $^{1}$, Xiaoming Wang ${ }^{1}$, Fengjie Yan ${ }^{1}$ \\ ${ }^{1}$ Laboratory of Grid Metals Corrosion and Protection, State Grid Shandong Electric Power Research \\ Institute, Jinan 250002, China; \\ ${ }^{2}$ State Grid HeZe Power Supply Company, Heze, 274000, China. \\ akevin_guo1986@hotmail.com, ${ }^{\text {b } 20393691 @ q q . c o m ~, ~}{ }^{c}$ 87946904@qq.com, ${ }^{d}$ Ixgeng@126.com
}

Keywords: thermal properties; corrosion analysis; salt spray; coatings, Zn-Al-Mg alloy.

\begin{abstract}
In this work, alloy coatings with different $\mathrm{Al}$ and $\mathrm{Mg}$ content have been prepared on overhead ground wires for $\mathrm{Zn}$-Al-Mg series hot-dip coatings providing good protection on mild steel surface against corrosion. A reinforced thermal stability is confirmed by DSC thermodynamic curves. Furthermore, the enhanced corrosion resistance is also observed by salt spray test at $35^{\circ} \mathrm{C}$ in terms of morphology, weight change. Those features have a direct synergistic effect for corrosion protection of overhead ground wires at different stages in heavy corrosion environment and attributes to the improved metallographic structures from certain ternary eutectic reaction in alloy solidification.
\end{abstract}

\section{Introduction}

Alloy series coatings have been widely proved to provide protection of steel surface against environmental corrosion for its high corrosion resistance with small coating weight and electrogalvanized coatings [1-4]. As increasing requirements for a longer service life in overhead ground wires, Zn-Al-Mg series coatings have attracted attention for excellent corrosion stability superior to that of $\mathrm{Zn}-\mathrm{Al}$ series coatings [5,6]. Many researchers are attracted with their phase structure which is prepared from $6 \mathrm{wt}$.\% Al baths [7,8]. Corrosion resistance has been increased in the content of Mg within 0.5 wt.\% -3 wt.\% [3,9,10].

Several commercial overhead ground wires for heavy corrosion atmosphere, such as Zn-55Al-0.2Si has been available through 1990s by Japanese and European research groups [11-16]. Some researchers found that corrosion inhibited by the buffering and formation of $\mathrm{Al}(\mathrm{OH})_{3}$ layered in $\mathrm{Zn}-\mathrm{Al}$ series coatings [17] which attributed to the enhanced corrosion performance of corrosion products in presence of $\mathrm{Mg}^{2+}$ ions [8,13]. Corrosion behaviors of alloy coatings in chloride and different anions containing environments have already been investigated $[11,14,18]$. However, the reason for thermodynamic characteristics is not clear and there is fewer explanations for the proposals of corrosion resistance mechanisms in tests as mentioned above. In this work, hot-dip Zn-5 wt.\% Al series, Zn-5 wt.\% Al-1 wt.\% Mg, Zn-6 wt.\% Al-3 wt.\% Mg series coatings are prepared on overhead ground wires and the properties in terms of salt spray test and thermal curves by DSC were investigated within this study.

\section{Materials and methods}

\subsection{Materials.}

Steel wire specimens of dimensions $100 \mathrm{~mm} \times 3.2 \mathrm{~mm}$, having composition Si-0.16, C-0.18, Mn-0.65, P-0.026, Mo-0.015, Ni-0.02 (all in wt.\%) and the rest of iron, were used as the substrate materials. The steel wires were degreased with $10 \% \mathrm{NaOH}$ aqueous solution at $50^{\circ} \mathrm{C}$ for $2 \mathrm{~min}$. After drying, the specimens were hot-dipped in Zn (99.99 \%purity) bath, Zn-Al bath, Zn-Al-Mg-RE bath, respectively. The composition of coatings which were formed in different alloy series and its characteristic parameter are given in Table 1. The coatings are all produced in self-made hot dipping 
equipment. After hot-dipping in alloy baths, the steel wires were cooled in air and then quenched in the water for seconds.

Table 1 The composition and characteristic parameter of different zinc-based coatings used in the study.

\begin{tabular}{ccccc}
\hline Materials & Zn & Zn-Al & \multicolumn{2}{c}{ Zn-Al-Mg-RE } \\
\cline { 4 - 5 } & & & Z-5A-1M & Z-6A-3M \\
\hline \multirow{2}{*}{ Al (mass \%) } & $0 \sim$ & $5 \pm 0.5$ & $5 \pm 0.5$ & $6 \pm 0.5$ \\
Mg (mass \%) & 0.2 & & & $3 \pm 0.2$ \\
RE (mass \%) & - & - & $1 \pm 0.1$ & $0.1 \pm 0.05$ \\
Thickness $(\mu \mathrm{m})$ & $95 \pm 5$ & $85 \pm 5$ & $75 \pm 5$ & $70 \pm 5$ \\
\hline
\end{tabular}

\subsection{NSS Corrosion test}

In this study, test methods are according to ISO 9227 (NSS). As specified in the standard a 2.6 wt.\% salt, regulated to $\mathrm{pH}$ 6.5-7.5, was sprayed with nozzles into an Erichsen spray testing chamber at a constant temperature of $34.5 \pm 0.5^{\circ} \mathrm{C}$. The test panels were arranged on a plastic sample holder at an angle of $45^{\circ}$ to vertical. The volume of the sprayed sulfuric acid solution was measured once a day by using a cone (diameter $100 \mathrm{~mm}$, which corresponds to a collecting area of $80 \mathrm{~cm} 2$ ) on a measuring cylinder collecting a defined fraction of the sulfuric acid solution for a period of $12 \mathrm{~h}$. During the entire test the volume of the collected solution was $41 \pm 2.5 \mathrm{ml} / 24 \mathrm{~h}$.

\subsection{Characterization}

The Surface morphology of steel wires were examined by using Scanning Electron Microscope (SEM). The phases in the hot-dip coatings were analyzed by XRD using Oxford diffractometer with $\mathrm{Cu} \mathrm{K \alpha}(\lambda=1.54060 \AA)$ incident radiation. The peaks of XRD were recorded in the $2 \theta$ range of $10^{\circ}-100^{\circ}$. The calorimetric analysis was carried out using a NETZSCH DSC 204F1 calorimeter in a nitrogen atmosphere, giving an accuracy of $\pm 0.1-0.3^{\circ} \mathrm{C}$ for the temperature, $\pm 18 \mu \mathrm{V} /(\mathrm{mW})$ for the energy measurements. The steel wire sample's mass was set from $8 \mathrm{mg}$ to $12 \mathrm{mg}$ within a pressurization crucible. The heating range was set from 0 to $350{ }^{\circ} \mathrm{C}$ at $1{ }^{\circ} \mathrm{C} / \mathrm{min}$ to obtain the thermal characteristic. Those tests were replicated about 3-5 times.

\section{Results and Discussion}

\subsection{XRD analysis of steel wires}

The measurement results show the measured XRD pattern obtained of steel wires with different contents of $\mathrm{Al}, \mathrm{Mg}, \mathrm{RE}$. In Fig. 1 (a) represents $\mathrm{Zn}$ coating, (b) for Zn-5\%Al-0.1\%RE, (c) for Zn-5\%Al-1\%Mg-0.1\%RE, (d) for Zn-6\%Al-3\%Mg-0.1\%RE, respectively.

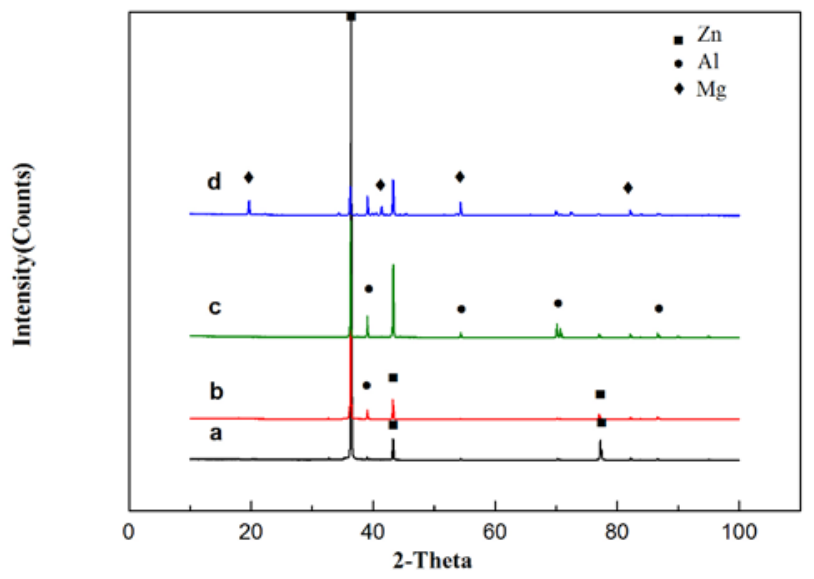

Fig.1. XRD patterns of alloy coatings, (a) Zn, (b) Zn-5\%Al, (c) Zn-5\%Al-2\%Mg-0.1\%RE, (d) Zn-6\%Al-3\%Mg-0.1\%RE.

The inhibiting effect of $\mathrm{Al}$ when compared to pure zinc coating attribute to the reduction in the columnar Fe-Zn compound content [2,20]. It is probable that steel wires alloy coatings are composed 


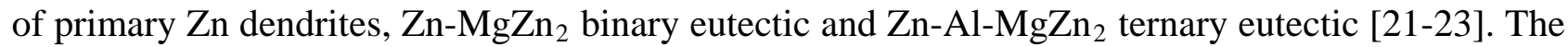
intensity of the peak due to $\mathrm{Zn}-6 \% \mathrm{Al}-3 \% \mathrm{Mg}-\mathrm{RE}$ consists of a large amount of magnesium and aluminum.

\subsection{Thermal stability analysis}

Thermodynamic modeling has been found to investigate corrosion via corrosion products of alloy coatings on steel wires [23]. The measurement results of steel wires alloy coatings with different contents of magnesium from $0 \mathrm{wt} . \%$ to $3 \mathrm{wt} . \%$ and aluminum from $0 \mathrm{wt} . \%$ to $6 \mathrm{wt} . \%$ had been given in Fig. 2. It can be expressed as Eq. (1) in most types of solid $\rightarrow$ solid + gas reactions $[27,28]$ :

$$
\frac{d \alpha}{d t}=A \exp \left(-\frac{E}{R T}\right)(1-\alpha)^{n}
$$

Where:

$$
\alpha=\frac{m_{s}-m}{m_{s}-m_{f}}
$$

As we known, $m, m_{\mathrm{s}}$ and $m_{\mathrm{f}}$ are the actual, initial and final mass of the samples, $A(\mathrm{~s}-1)$ is the pre-exponential factor, $R(\mathrm{~J} / \mathrm{mol} \mathrm{K})$ is the gas constant energy, $T(\mathrm{~K})$ is the temperature, $E(\mathrm{KJ} / \mathrm{mol})$ is the activation and $n$ is the reaction order. For a linear heating process with constant heating rate [5], $\beta-\mathrm{d} T / \mathrm{d} t(\mathrm{~K} / \mathrm{min})$ in Eq. (1), can be expressed as:

$$
\frac{d \alpha}{(1-\alpha)^{n}}=\frac{A}{\beta} \exp \left(-\frac{E}{R T}\right) d T
$$

In Kissinger's method [28], the maximum reaction rate occurs when $\mathrm{d}(\mathrm{d} a / \mathrm{d} t)=0$ :

$$
\frac{E \beta}{R T_{M}^{2}}=A n(1-\alpha)_{m}^{n-1} \exp \left(-\frac{E}{R T_{m}}\right)
$$

We can substitute an approximate solution to Eq. (3) and combine with Eq. (4) for $T_{\mathrm{m}}$ is the temperature where the maximum rate occurs:

$$
\frac{d\left(\ln \frac{\beta}{T_{m}^{2}}\right)}{d\left(\frac{1}{T_{m}}\right)}=-\frac{E}{R}
$$

It is seen that the product $n(1-\alpha)_{m}^{n-1}$ is very nearly to 1 . So, we substitute this value to eq. (4):

$$
A=\frac{\frac{E \beta}{R T_{M}^{2}}}{\exp \left(-\frac{E}{R T_{m}}\right)}
$$

Introducing Eq. (6) bring us that the plot of $E \beta / R T^{2}{ }_{\mathrm{m}}$ versus exp (-E/RT $T_{\mathrm{m}}$ ) results in a straight line of slope A. The kinetic parameters of thermal degradation of steel wires alloy coatings materials are shown in Fig.2.

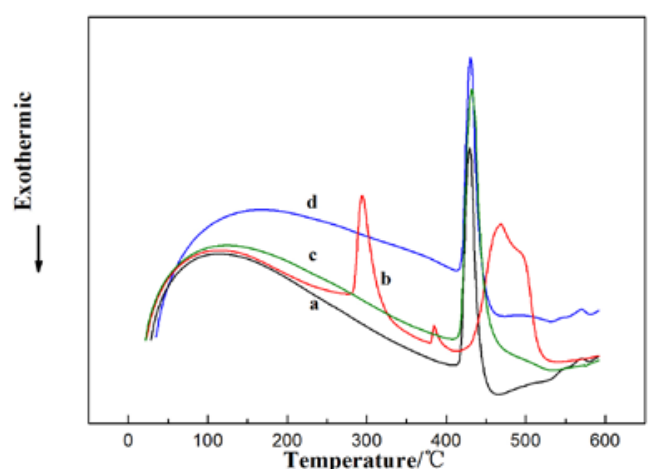

Fig.2. DSC curves of mild steel samples deposited with alloy coatings, (a) Zn, (b) Zn-5\%Al, (c) Zn-5\%Al-2\%Mg-0.1\%RE, (d) Zn-6\%Al-3\%Mg-0.1\%RE. 
It is proposed that the higher thermal stability represent the better anti-corrosion properties of DSC

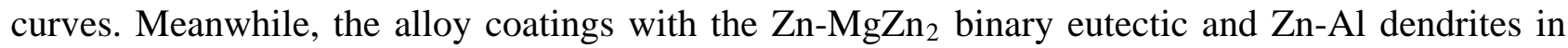
terms of a different reaction mechanism during increasing magnesium causes the conversion of ternary eutectic reaction to improve the addition in distribution of ternary eutectic group with subsequent outer alloy layer matrix of Zn-Al-Mg coatings on mild steel substrate.

\subsection{Corrosion behavior of steel wires coatings}

\subsubsection{Surface analysis by SEM}

The steel wires surface images of Zn-Al, Zn-Al-Mg samples after salt spray corrosion test were shown in Fig.3. The dissolution of coatings surface is clearly observed. Zn coating surface has been widely corroded which has been shown in Fig. 3(a). The increasing degree of crystalline coverage and reducing of the size of the zinc crystals promote the anti-corrosion properties of coatings layer as shown in Fig. 3(b).
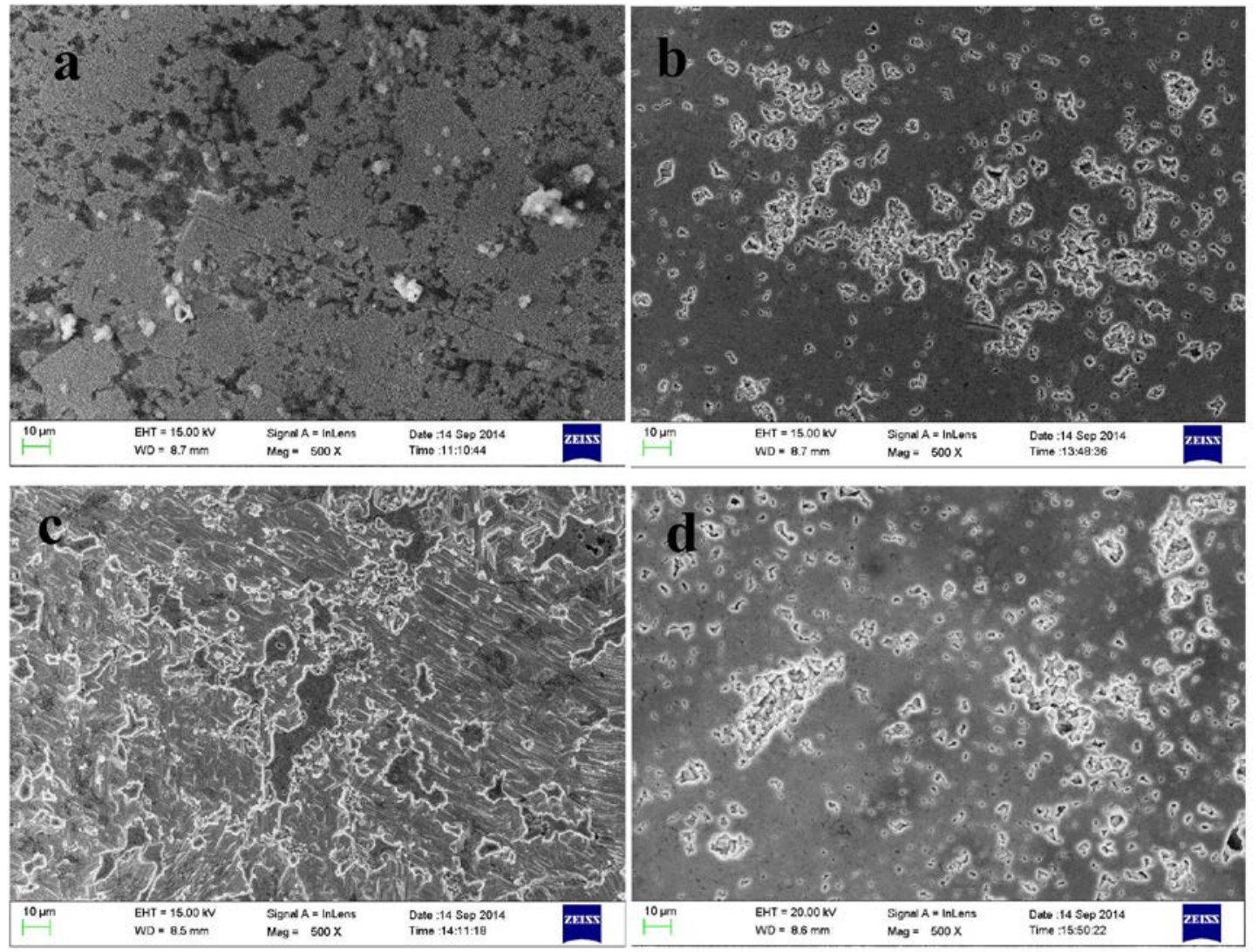

Fig.4. SEM images of alloy coatings surface after sulfuric acid spray test, (a) Zn, (b) Zn-5\%Al, (c) Zn-5\%Al-2\%Mg-0.1\%RE, (d) Zn-6\%Al-3\%Mg-0.1\%RE.

For the conversion of ternary eutectic reaction by adding magnesium, the corrosion resistance has been improved and remained uncorroded after salt spray corrosion. Fig. 3(c) show the changes in micromorphology of the outer layer with corrosion for $\mathrm{Zn}-5 \% \mathrm{Al}-1 \% \mathrm{Mg}$-RE. The crystal clusters of coatings obtained from the baths containing Mg with $3 \mathrm{wt} . \%$ are denser and larger than others according to SEM photograph. Those surface structures which have been corroded in salt spray measurement have excellent anti-corrosion capability as presented in Fig. 3(d). Accordingly, the incorporation of $3 \mathrm{wt} \% \mathrm{Mg}$ and $0.1 \mathrm{wt} . \%$ rare earth element in to the Zn-Al-Mg-RE bath has remained crystal little unchanged and also helped to achieve excellent surface anti-corrosion ability based on surface analysis.

\subsubsection{Coatings weight change}

The specimens were exposed to salt spray test for different periods. Fig. 4 shows weight change data after $1700 \mathrm{~h}$ of the tested samples surface in the heavy salt spray test (NSS). The mass of galvanized was increased rapidly in the beginning giving rise to $0.7 \mathrm{~g} / \mathrm{m}^{2}$ in first $200 \mathrm{~h}$. The weight of Zn has been increased, which will ultimately result into accelerated corrosion products generated. The remarkable growth parts are the preferentially corroded areas of $\mathrm{Zn}$ and $\mathrm{Zn}-5 \mathrm{Al}$ coatings and 
there are some huge increase area of corrosive in the surface, which may lead to the further corrosion. After $400 \mathrm{~h}$. By contrast different coated steel shows mass loss trend after 530h. It is important that the corrosion resistance of coatings metallographic structure is visual in this stage. It is clear from the figure that when the $\mathrm{Al}$ content in coating alloy is increased, corrosion weight loss decreases, evidencing an improvement in the corrosion resistance by increase the number of eutectic group, hypoeutectic structure, hypereutectic structure composed of primary $\alpha$-Al phase. It is also clearly observed from the figure that, when the Mg content in alloy is increased, corrosion weight loss decreases, showing that the corrosion resistance of plating is improved by increasing multiphase structure of $\mathrm{Zn}-\mathrm{MgZn}_{2}$ binary eutectic, $\mathrm{Zn}-\mathrm{Al}$ dendrites and ternary eutectic $\mathrm{Zn}-\mathrm{Al}-\mathrm{MgZn}_{2}$. The steel wire samples coated with zinc red rust already appears after $800 \mathrm{~h}$ and spreads rapidly over the entire sample surface. Some heavy red etch pits are observed in large distribution area after $1000 \mathrm{~h}$.

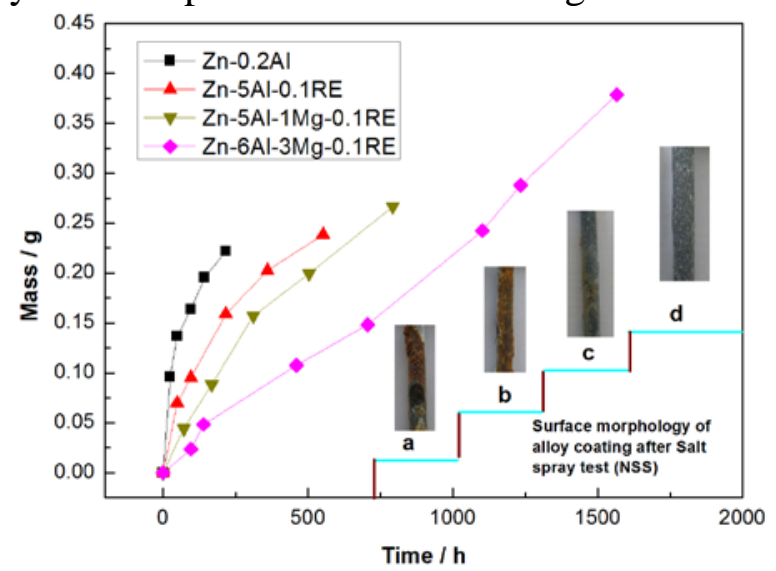

Fig.4. Weight change of alloy coating exposure to salt spray with 2000h, (a) Zn, (b) Zn-5\%Al, (c) Zn-5\%Al-2\%Mg-0.1\%RE, (d) Zn-6\%Al-3\%Mg-0.1\%RE.

Accordingly corrosion progress is very slow with only slight increases in white rust and no red rust even after $1500 \mathrm{~h}$ of $\mathrm{Zn}-6 \mathrm{Al}-3 \mathrm{Mg}$. The noticeable different areas on the samples of Zn-Al-Mg has a decisive enhanced corrosion performance in the salt spray test compared to $\mathrm{Zn}$. The auxiliary visual inspection shows considerable differences between both coating systems after test as also shown in Fig. 4.

\section{Conclusion}

In this work, a reinforced thermal stability of DSC curves is confirmed by thermal analysis at overhead ground wires surface, which attribute to uniform microstructure derived from ternary eutectic reaction in alloy solidification. The enhanced corrosion resistance is observed by unique anti-corrosion properties of different coatings in salt spray at $45^{\circ} \mathrm{C}$ in terms of morphology, weight change. This feature might have a direct effect for corrosion protection of alloy coatings in heavy corrosion environment. Therefore, it is proposed that thermal stability in terms of improvement metallographic structure by addition of magnesium and aluminum element, could ensure stable passivity in salt spray environment and limits the efficiency of corrosion reduction on overhead ground wires surface.

\section{References}

[1] P. Puomi, H.M. Fagerholm, J.B. Rosenholm, Comparison of different pretreatment-primer systems on hot-dip galvanized and Galfan coated steel, Anti-Corrosion Methods and Materials. 46(1999) 163-172.

[2]M. Vlot, R. Bleeker, T. Maalman, E.van Perlstein, MagiZinc TM, A new generation of hot-dip galvanised products, in: Proc. Galvanized Steel Sheet Forum 2006. Dusseldorf, 2006.

[3] Edavan R P, Kopinski R, et al. Corrosion resistance of painted zinc alloy coated steels, Corrosion Science. 51 (2009) 2429-2442. 
[4] R. Hausbrand, M. Stratmann, M. Rohwerder, Delamination resistant zinc alloys: simple concept and results on the system zinc-magnesium, Steel Research Int. 74 (2003) 453-458.

[5] S. Schuerz, M. Fleischanderl, G.H. Luckeneder, Corrosion behavior of Zn-Al-Mg coated steel sheet in sodium chloride-containing environment, Corrosion Science. 51 (2009) 2355-2363.

[6] Li Qian, Zhao Yang-zi, Luo Qun, Experimental study and phase diagram calculation in Al-Zn-Mg-Si quaternary system, Journal of Alloys and Compounds. 501 (2010) 282-290.

[7] Junichi TANAKA, Keisuke ONO, Shigenari HAYASHI, Effect of $\mathrm{Mg}$ and $\mathrm{Si}$ on the Microstructure and Corrosion Behavior of Zn-Al Hot Dip Coatings on Low Carbon Steel, ISIJ International, 42 (2002) 80-85.

[8] T. Prosek a, D. Persson, J. Stoulil, D. Thierry, Composition of corrosion products formed on $\mathrm{Zn}-\mathrm{Mg}$, Zn-Al and Zn-Al-Mg coatings in model atmospheric conditions, Corrosion Science. 86 (2014) 231-238.

[9] T.A. Keppert, G. Luckeneder, K.H. Stellnberger, G. Mori, H. Antrekowitsch, Investigation of the Corrosion Behavior of Zn-Al-Mg Hot-Dip Galvanized Steel in Alternating Climate Tests, Corrosion. 70 (2014) 1238-1248.

[10] N. LeBozec, D. Thierry, A. Peltola, L. Luxem, G. Luckeneder, G. Marchiaro, M. Rohwerder, Corrosion performance of $\mathrm{Zn}-\mathrm{Mg}$-Al coated steel in accelerated corrosion tests used in the automotive industry and field exposures, Materials and Corrosion. 64 (2013) 969-978.

[11] T. Prosek, N. Larche', M. Vlot. Corrosion performance of Zn-Al-Mg coatings in open and confined zones in conditions simulating automotive applications, Materials and Corrosion. 61(2010) 412-420.

[12] K. Tano, S. Higuchi. Development and properties of zinc-aluminum alloy coated coated steel sheet with high corrosion resistance (super zinc), Nippon Steel Technical Report, 25 (1985) 29-34.

[13] T. Prosek, D. Thierry, C. Taxen, J. Maixner, Effect of cations on corrosion of zinc and carbon steel covered with chloride deposits under atmospheric conditions, Corrosion Science.49 (2007) 2676-2682.

[14] S. Schuerz, G.H. Luckeneder, M. Fleischanderl, P. Mack, H. Gsaller, A.C. Kneissl, G. Mori, Chemistry of corrosion products on Zn-Al-Mg alloy coated steel, Corrosion Science. 52 (2011) 3271-3280.

[15] J. Duchoslav, M. Arndt, R. Steinberger, T. Keppert, G. Luckeneder, K.H. Stellnberger, Nanoscopic view on the initial stages of corrosion of hot dip galvanized Zn-Mg-Al coatings, Corrosion Science. 83 (2014) 327-334.

[16] N. LeBozec, D. Thierry, M. Rohwerder, D. Persson, G. Luckeneder, L. Luxem, Effect of carbon dioxide on the atmospheric corrosion of Zn-Mg-Al coated steel, Corrosion Science. 74 (2013) 379-386.

[17] P. Volovitch, T.N. Vu, C. Alley, Understanding corrosion via corrosion product characterization: II. Role of alloying elements in improving the corrosion resistance of Zn-Al-Mg coatings on steel, Corrosion Science. 53 (2011) 2437-2346.

[18] J. Duchoslav, M. Arndt, R. Steinberger, T. Keppert, G. Luckeneder, K.H. Stellnberger, J. Hagler, Nanoscopic view on the initial stages of corrosion of hot dip galvanized Zn-Mg-Al coatings, Corrosion Science. 83 (2014) 327-334.

[19] Nathalie LeBozec, Dominique Thierry, Michael Rohwerder, Dan Persson, Gerald Luckeneder, Effect of carbon dioxide on the atmospheric corrosion of $\mathrm{Zn}-\mathrm{Mg}$-Al coated steel, Corrosion Science. 74 (2013) 379-386.

[20] J. Elvins, J.A. Spittle, J.H. Sullivan, D.A. Worsley, The effect of magnesium additions on the microstructure and cut edge corrosion resistance of zinc aluminium alloy galvanised steel, Corrosion Science. 50 (2008) 1650-1658.

[21] E. de Bruycker, Z. Zermout, B.C. De Cooman, Zn-Al-Mg coatings: thermodynamic analysis and microstructure related properties, Mater. Sci. 539 (2007) 1276-1281. 
[22] R. Hausbrand, M. Stratmann, M. Rohrwerder, The physical meaning of electrode potentials at metal surfaces and polymer/metal interfaces: consequences for delamination, J. Electrochem. Soci. 155 (2008) C 369-C379.

[23] R. Hausbrand, M. Stratmann, M. Rohwerder, Delamination resistant zinc alloys: simple concept and results on the system zinc-magnesium, Steel Res. Int. 74 (2003) 453-458.

[24] S. Sugimaru, S. Tanka, Zinc alloy coated steel wire with high corrosion resistance, Nippon Steel Technical Report, 96 (2007) 34-38.

[25] W. Yuansheng, X. Ji, Oxidation resistance and corrosion behavior of hot-dip aluminized coatings on commercial-purity titanium, Surface \& Coatings Technology, 206 (2011) 1277-1282.

[26] Ying Zhaoa, Guosong Wub, Jiang Jiang, Hoi Man Wonga, Kelvin W.K. Yeunga, Paul K. Chub. Improved corrosion resistance and cytocompatibility of magnesium alloy by two-stage cooling in thermal treatment. Corrosion Science, 59 (2012) 360-365.

[27] P. Volovitch, T.N. Vu, C. Allely, A. Abdel Aal, K. Ogle. Understanding corrosion via corrosion product characterization: II. Role of alloying elements in improving the corrosion resistance of Zn-Al-Mg coatings on steel, Corrosion Science, 53 (2011) 2437-2445.

[28] E. de Bruycker, Z. Zermout, B.C. Cooman, Zn-Al-Mg coatings: thermal dynamic analysis and microstructures related properties, Material Science Forum, 539 (2007) 1276-1281.

[29] J. Duchoslava, R. Steinbergera, M. Arndta, T. Keppertb, G. Luckenederb, D. Stiftera, Evolution of the surface chemistry of hot dip galvanized $\mathrm{Zn}-\mathrm{Mg}-\mathrm{Al}$ and $\mathrm{Zn}$ coatings on steel during short term exposure to sodium chloride containing environments. Corrosion Science. 91 (2015) 311-320.

[30] M. Salgueiro, Azevedoa, C. Allélyb, K. Oglea, P. Volovitcha. Corrosion mechanisms of Zn(Mg, $\mathrm{Al})$ coated steel in accelerated tests and natural exposure: 1 . The role of electrolyte composition in the nature of corrosion products and relative corrosion rate. Corrosion Science. 91 (2015) 311-320. Corrosion Science. 90 (2015) 472-481.

[31] E. Diler, B. Lescop, S. Rioual, G. Nguyen Vien, D. Thierry, B. Rouvellou, Initial formation of corrosion products on pure zinc and $\mathrm{MgZn}^{2}$ examinated by XPS, Corrosion Science. 79 (2014) 83-88.

[32] S. Schürz, G.H. Luckeneder, M. Fleischanderl, P. Mack, H. Gsaller, A.C. Kneissl. Chemistry of corrosion products on Zn-Al-Mg alloy coated steel, Corrosion Science 52 (2010) 3271-3279.

[33] M. Dutta, A. K. Halde, S. B. Singh. Morphology and properties of hot dip Zn-Mg and Zn-Mg-Al alloy coatings on steel sheet. Surface and Coatings Technology, 205(2010) 2578-2584.

[34] Rajiv P. Edavan, Richard Kopinski. Corrosion resistance of painted zinc alloy coated steels, Corrosion Science 51 (2009) 2429-2442.

[35] J. Klein, J. Schneider, M. Muske, and Aluminum induced crystallization of amorphous silicon: Influence of the aluminum layer on the process. Thin Solid Films, 451 (2004) 481-484. 